\title{
On the Efficiency of Use of Seismic Isolation in Antiseismic Construction
}

\author{
Tatiana Belash ${ }^{1}$, Ulugbek Begaliev², Sagynbek Orunbaev ${ }^{3}$, Marat Abdybaliev² \\ ${ }^{1}$ The Faculty of Industrial and Civil Engineering, Emperor Alexander I St. Petersburg State Transport University, Saint Petersburg, Russia \\ ${ }^{2}$ International University of Innovation Technology, Bishkek, Kyrgyzstan \\ ${ }^{3}$ Central Asian Institute of Applied Geosciences, Bishkek, Kyrgyzstan
}

\section{Email address:}

s.orunbaev@caiag.kg (S. Orunbaev)

\section{To cite this article:}

Tatiana Belash, Ulugbek Begaliev, Sagynbek Orunbaev, Marat Abdybaliev. On the Efficiency of Use of Seismic Isolation in Antiseismic Construction. American Journal of Environmental Science and Engineering. Vol. 3, No. 4, 2019, pp. 66-74. doi: 10.11648/j.ajese.20190304.11

Received: March 6, 2019; Accepted: April 13, 2019; Published: November 5, 2019

\begin{abstract}
The main issues of evaluating the efficiency of use of the seismic isolation systems as a reliable means of seismic protection of buildings and structures in seismically hazardous regions have been analysed. Specific characteristics of the most common types of seismic isolation in case of seismic load considered. It is shown that these protection systems are now becoming more common, without their respective justification. In this regard, there is a need to develop special recommendations for the use of seismic insulation in the construction of buildings and structures for various purposes. At the same time, special attention is paid to the effective conFigureuration of seismic isolation and the role of damping in it. The possibility of application of the considered protection should include: an assessment of the seismological situation of the construction area, technical and economic analysis of the choice of the type of seismic insulators, a complex of computational, theoretical and experimental studies.
\end{abstract}

Keywords: Seismic Resistance, Seismic Isolation, Elastic Supports, Dampers

\section{Introduction}

Seismic isolation is usually understood as a system for reducing the energy impact on a structure during seismic vibrations by installing elements of increased elasticity that make it possible to tune the response spectrum of the building away from the impact spectrum in the long period range $[1,2]$.

The idea of using seismic isolation known since ancient times. For example, in Central Asia, ancient architects installed special pillows made of granular materials under the foundations of worship buildings. Due to the nonlinear response of these materials, the seismic vibrations of such facilities during earthquakes significantly decreased [3]. Despite the simplicity and affordability of the engineering implementation, the idea of seismic isolation was not widespread for a long time. However, the situation changes significantly with the development of the theory of seismic resistance at the beginning of the 20th century. Since the mid-1950s, the common approach was to replace the static method of structural engineering by the spectral one for evaluation of seismic effect. In accordance with the spectral calculation method adopted in regulatory documents, the formula for determining the seismic load included the dynamic response factor $\beta[4,5]$, which depended on the natural period of vibrations of the structure $(T)$. The linear connection $\beta(T)$ called the spectral curve, which constructed using data on characteristics and performance of the largescale residential development during destructive earthquakes. With increasing $T$ there is a significant decrease in the value of the factor $\beta$. An example of the effect of seismic isolation shown in Figure 1.

This circumstance served as an incentive for active use and implementation of seismic isolation systems in seismic resistant construction in many countries with high seismic activity, which continues up to the present days.

Over the past decade, all global conferences devoted to seismic isolation have seen an increase in the number of seismically isolated buildings in seismically dangerous 
regions of the world. These data given, for example, in papers $[6,7]$. Japan ranks number one in terms of the number of implemented systems of special seismic insulation. It was in this country that the seismic resistance of seismically isolated facilities proved effective during the earthquake in the city of Kobe in 1995. None of them damaged. This was the impetus for a sharp increase in the construction of buildings with seismic isolation systems. In Japan, particular attention paid to the importance of use of seismic isolation systems in education and health care buildings, as well as transport facilities. High technological level of implementation of seismic isolation also noted, as well as a large range of studies conducted in this area.

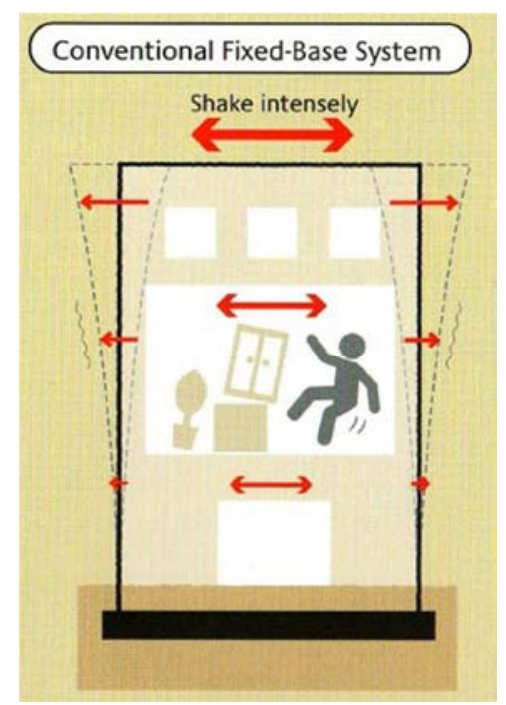

a)

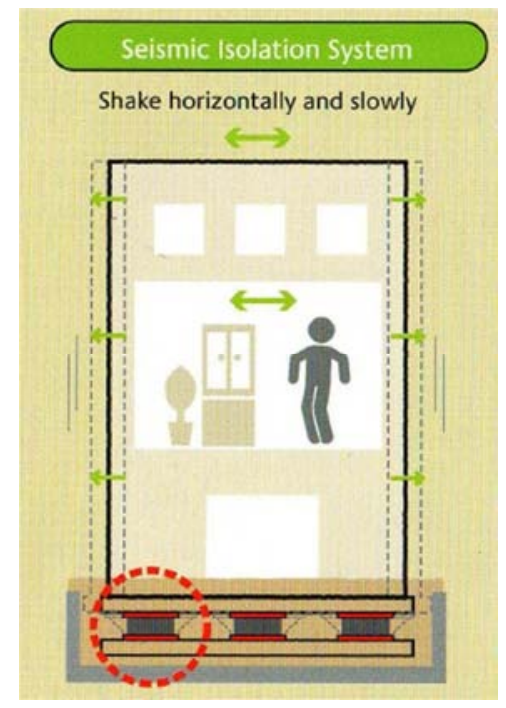

b)

Figure 1. Performance of ordinary (a) and seismic insulated (b) building during earthquake.

The United Stated of America was one of the first countries in which seismic isolation began used. A great contribution to the development of this protection system made by Professor J. M. Kelly [8, 9]. Hundreds of seismically isolated buildings built in the United States, including various administrative buildings, museums, large industrial facilities, etc., which are subject to the increased safety requirements.

China is a country that made an important breakthrough in the use of seismic isolation systems in modern earthquakeresistant development. In 1993, the first seismic insulated building built in China. Nowadays, this country is among the world leaders in terms of use of seismic isolation systems. After severe earthquakes that occurred in China (more than $60 \%$ of the territory is located in seismically dangerous zones), the government of this state decided to create a special program to ensure safety of the population in case of earthquakes. The country has established several state institutions for antiseismic engineering: in Beijing, Shanghai, Guangzhou. Hundreds of seismically isolated buildings built in China, including Subway Hub, the largest seismic insulated complex consisting of fifty 7-9-storey buildings with a total area of $480,000 \mathrm{~m}^{2}$, which is the largest area in the world with the use of seismic insulation.

About 550 buildings are seismically isolated in Russia, with more than 500 built during the time of the former USSR. The largest number of seismically isolated buildings erected in Kazakhstan, the Kyrgyz Republic, Primorsk Territory, Siberia, and Kamchatka and in other seismically hazardous locations. Seismic isolation has become widespread in the Russian Federation during the preparation for the Winter Olympic Games in Sochi. It used in buildings and structures for various purposes.

This protection system has recently become more and more widespread; this is due to the use of seismic isolation design standards, and the development of various innovative technologies in many countries around the world. This system is becoming increasingly widespread in Italy, Taiwan, New Zealand, Turkey, Chile, Mexico, Greece, Armenia and other countries.

Seismic isolation implemented in various ways. The simplest idea was the construction of a flexible first floor (Figure 2). Orunbaev [25] shows an experience on microseismic and vibroseismic testing of a residential two floor house in Bishkek, Kyrgyzstan. Comparative study shows a possibility to use microseismics for assessment of fundamental period of the building.

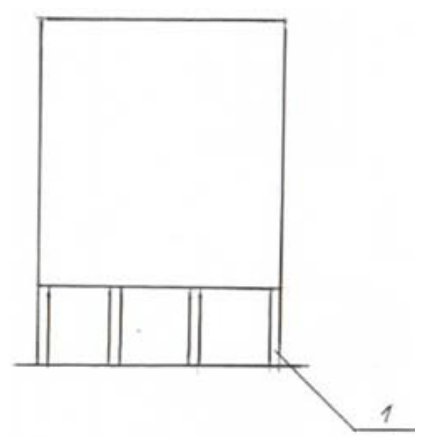

a) 


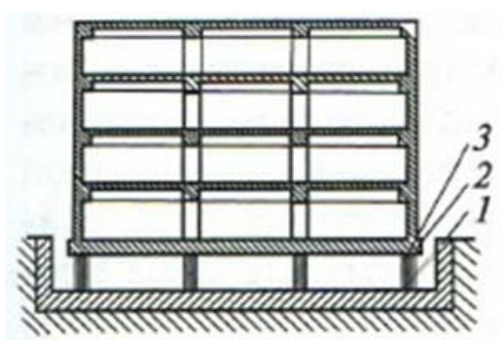

b)

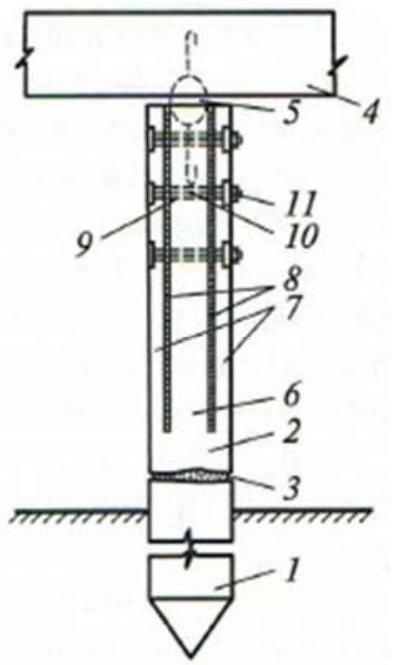

c)

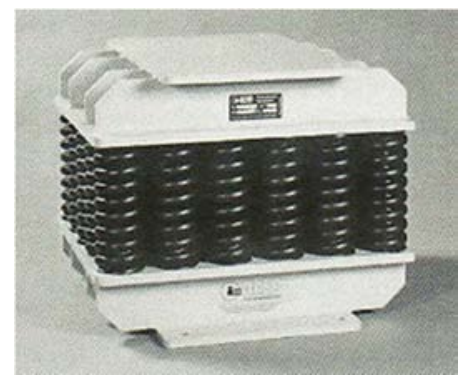

d)

Figure 2. Examples of implementation of the elastic elements of seismic isolation: a) buildings with a "flexible" ground floor: 1 -frame pillars; b) building on flexible supports made of a package of elastic rods: 1 - elastic supports; 2 and 3 - parts of the building; c) pile foundation design with an elevated pile foundation grillage, proposed by A. T. Aubakirov: 1, 2-piles of the lower and upper parts; 3 - cement-sand mortar; 4 - grillage; 5 hinge; 6, 7 -bars; 8 - laying; 9 - holes; 10 - bolts; 11 - nuts; d) elastic linear spatial (3D) support consisting of a set of coiled springs.

Such buildings built in many countries of the world. The role of the flexible ground floor performed by the frame pillars, pile foundation with an elevated pile foundation grillage, various elastic elements, for example, a set of elastic rods. Seismic loads reduced by arranging elastic support elements in the form of suspensions. The suspension type design implemented by F. D. Zelenkov in Ashgabat after a severe earthquake (Figure 3) [10]. This seismic protection based on two principles: an oscillating pendulum with a point of suspension and a spring buffer, which serves to reduce the seismic energy of vertical seismic effects.

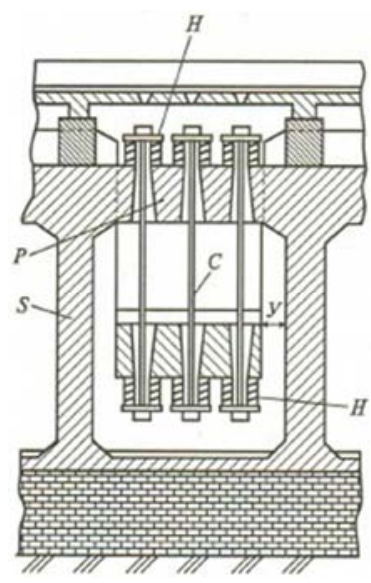

Figure 3. Suspension type seismic insulator in the building foundation: $y$ is the air gap providing free seismic vibrations of the building; $H$-springs; $C$ - steel suspension; $P$ - reinforced concrete bolts; $S$ - reinforced concrete frame pillars.

In the foreign countries, i.e., in the USA, New Zealand, France and other countries, seismic isolating supports are widely used in the form of spherical (ball) supports or rubber-metal supports. Such supports produced by Maurer Sohnes, FIP Industrial and others. Examples of such supports given in Figure 4.

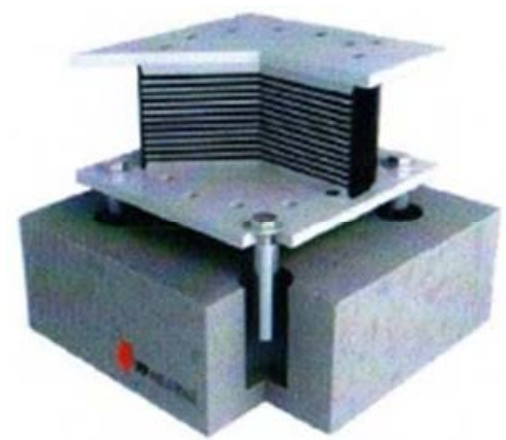

a)

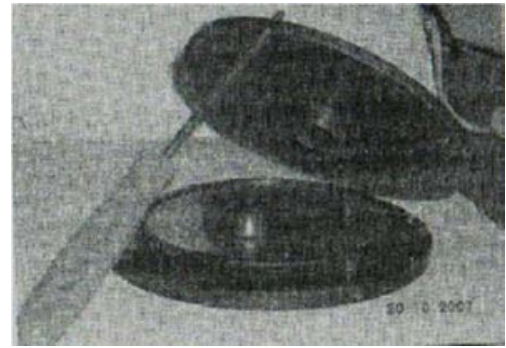

b)

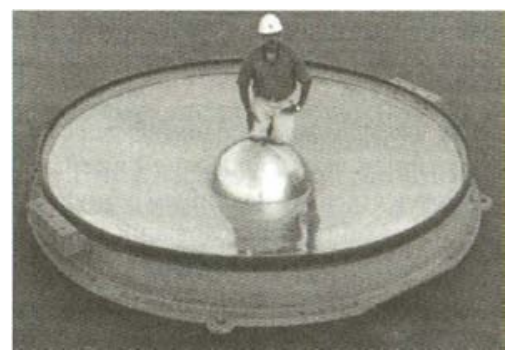

c) 


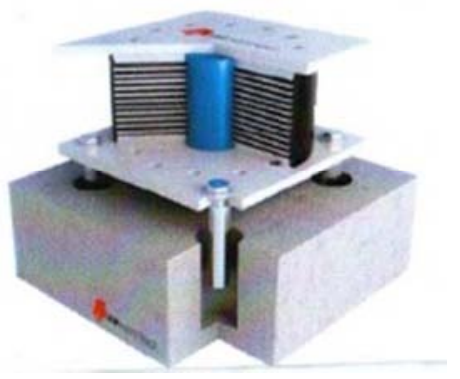

d)

Figure 4. Seismic isolators in the form of: a) supports of high damping rubber; b) lead core supports; c) spherical (ball) supports.

In Russia and Kazakhstan, as well as other republics of the former USSR, gravitational type seismic isolation has become widely spread. Examples of this seismic isolation shown in Figure 5.

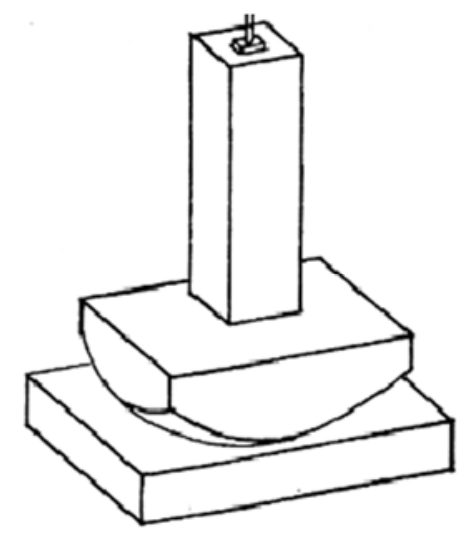

a)

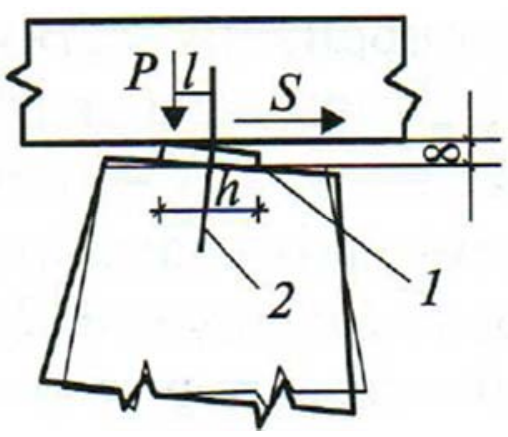

b)

Figure 5. Rocking column developed by Yu.D. Cherepinsky: a) a general view of the support; $b$ ) hinge joint of the support: 1 - tile; 2 - connecting anchor.

The principle of work of such structures is that during an earthquake, the center of gravity of the supports rises, resulting in generation of a gravitational restoring force. A great contribution to the development of this system of seismic isolation was made in the research institute "KazpromstroyNIIproekt" under the leadership of T.Zh. Zhunusov [11]. Yu.D. Cherepinsky was the author of the supporting elements $[12,13]$. Buildings on such supports were built in Almaty, Petropavlovsk-Kamchatsky and other cities of the former USSR. In addition to the supports developed by Yu. D. Cherepinsky, supports developed by V. V. Nazin and A. M. Kurzanov were also used in construction.

In civil engineering, the foundation with a seismic insulating sliding belt developed by L. Sh. Kilimnik, L. A. Soldatova, S. V. Polyakov and V. P. Chudnitsov, has become very popular $[14,15]$. This foundation is shown in Figure 6.

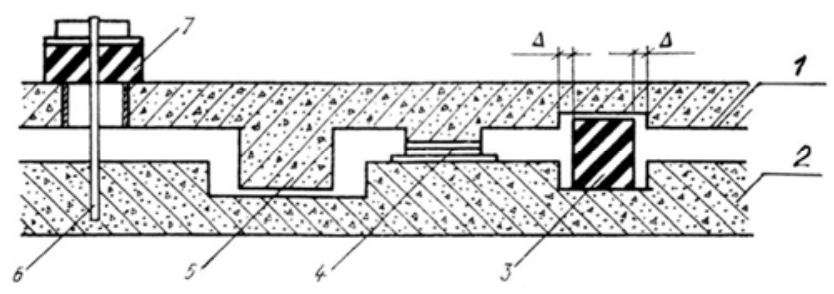

Figure 6. Seismic isolation belt design: 1 - upper foundation plate; 2 lower foundation plate; 3 -elastic horizontal movement limiter; 4 -sliding support; 5 - hard horizontal movement limiter; 6 - vertical movement limiter; 7 -vertical shock absorber.

It has a top connection and a grillage, between which fluoroplastic sheets and movement limiters are inserted. When seismic loads are applied to a building, relative shift between the grillage and the top connection takes place, which reduces the loads to the value of friction forces between the fluoroplastic sheets. Building movements are limited by specially mounted motion limiters. These seismic insulating foundations were implemented in Bishkek, the capital of the Kyrgyz Republic.

All the above examples of seismic isolation are systems in which dynamic characteristics are preserved during an earthquake. Along with the above solutions, adaptive systems, which are shown in Figure 7, have become popular in antiseismic construction in the Russian Federation. This seismic isolation system has been studied in detail in the papers of Ya. M. Eisenberg [17].

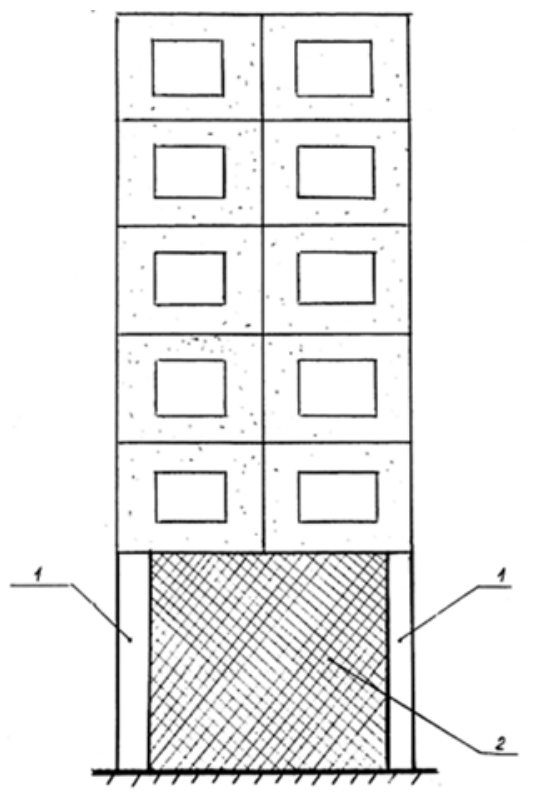

a) 


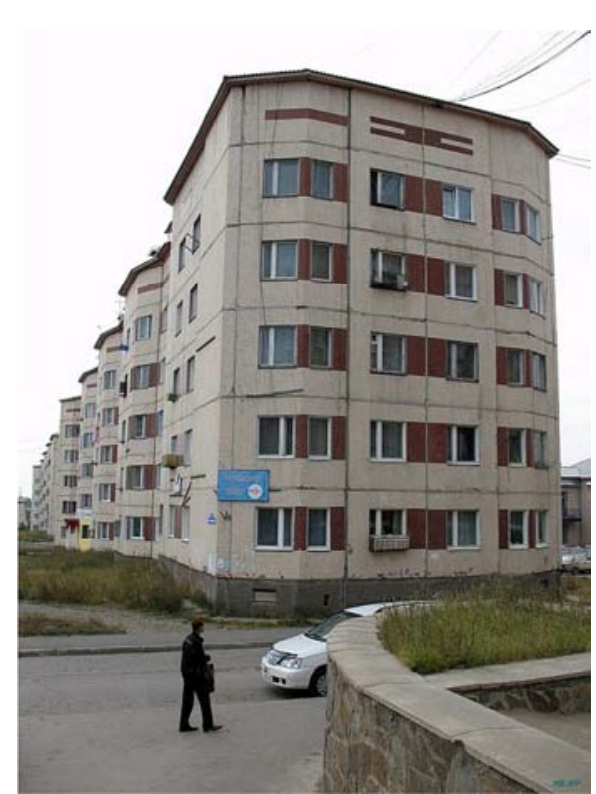

b)

Figure 7. Adaptive seismic protection system by Ya. M. Eisenberg: a) general scheme of seismic protection system: 1 - bearing racks of the ground floor; 2 - connection panels; b) the facade of 122 series building in Severobaykalsk, where an adaptive seismic protection system is used.

Along with the examples of seismic isolation discussed above, the patent and technical literature also offers a large number of other solutions coming from various specialists working in the field of seismic isolation. However, any solution, both existing and proposed ones, shall necessarily be justified using estimate and experimental research methods. Otherwise, a situation similar to that which occurred in the buildings with a "flexible" ground floor after severe earthquakes, for example, in the cities of Skopje, Bucharest and Mexico, may take place. Buildings with a "flexible" lower part during these earthquakes were seriously damaged and, in some cases, collapsed. The reason was presence of low-frequency components with amplitudes measured in tens of centimetres in the spectrum of these earthquakes. When complete seismic isolation is achieved, these shifts appear as relative shifts between the base and the isolated facility. In this situation it is difficult, and sometimes extremely difficult, to ensure the strength and stability of the seismic isolation elements.

Thus, the assessment of effectiveness of seismic isolation, as a reliable means of seismic protection of buildings and structures, during earthquakes significantly depends on solving a number of issues related to specific features of design of these systems, their calculation, construction and operation. Some of them are covered in this article.

\section{Methods}

\subsection{Technical and Economic Assessment}

When making a decision on use of seismic isolation of a building or a structure as a means of seismic protection, first of all, it is necessary to assess the following circumstances.
Considering that seismic isolation elements (examples of design solutions are given above) are made using special technologies, these elements are rather expensive.

In addition to seismic loads on buildings and structures, there are other loads, for example, wind load, which can be comparable to the seismic load; in view of the above, a large decrease in seismic load is not required and does not make sense.

At the stage of construction and operation of the facility it is of particular importance to assess the influence of engineering and geological as well as nature and climatic factors of the construction area, especially when using special supports, for which special precautions and safety measures are required.

When operating this protection system, additional material resources are required to maintain it in a continuous operating mode.

Based on the above, it is possible to make a conclusion that use of seismic isolation significantly increases the cost of construction as compared to commonly used reinforcement, and in this case its use is not always feasible. If, after the evaluation of all the circumstances, a decision is made to use seismic isolation, then the next step is to choose the type of isolation and to justify its feasibility.

While making the justification, it is necessary to take into account specific characteristics and performance of seismic isolated buildings and structures during earthquakes. Their performance is significantly affected by low-frequency seismic effects, accompanied by excessive amplitudes of base oscillations. In the research paper [18], it was shown that for seismically isolated facilities, the seismic hazard is determined by the maximum amount of shifts of the base during oscillatory movements. Therefore, the effectiveness of seismic isolation is achieved not only by the presence of flexible, elastic elements, but also by the presence of special damping devices that help to limit dangerous shifts. Examples of damping devices are shown in Figure 8 [2].

\subsection{Computational and Theoretical Assessment}

The task of estimating and selecting the parameters of seismic isolating devices begins with the construction of computational models and recording the motion equations. Considering different design solutions for seismic isolating foundations, to describe their oscillations, it becomes necessary to use different types of differential motion equations. While the most complex equations are characteristic of gravitational-type seismic isolation systems, since for them it is necessary to take into account the possible effects of "blocking" of supports during movement. The same difficulties arise for other design solutions, for example, when using dry friction dampers, in case of presence of nonlinear elements of various types during movement of the bond beam, etc.

Correct formulation and evaluation of the solution to the equations of motion of a seismically isolated facility significantly affect the efficiency of the adopted seismic isolation system and help to understand its operation during 
an earthquake. Therefore, it is important to supplement the calculation models with experimental data and characteristics that clarify the physical meaning of the work of the elements of seismic isolation.
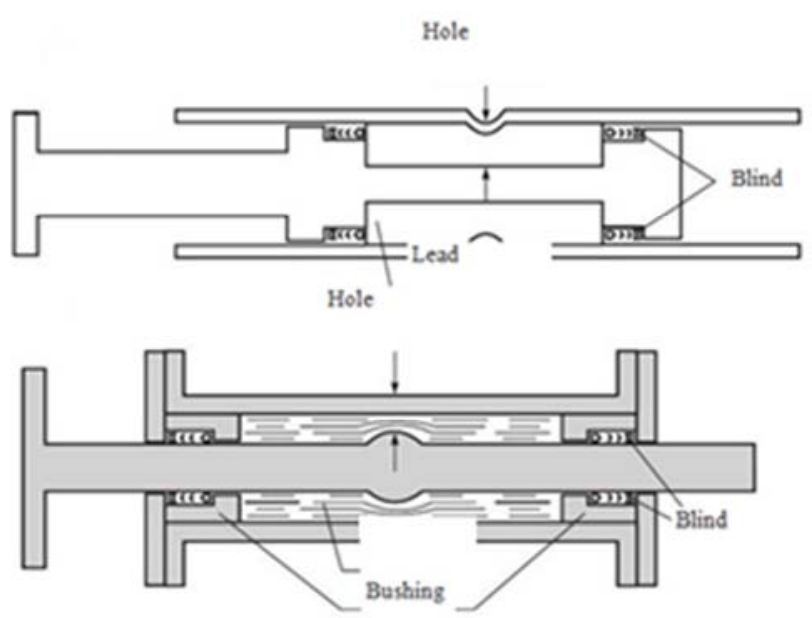

a)

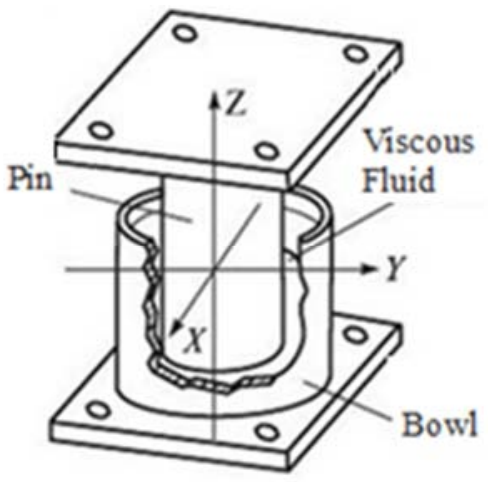

b)

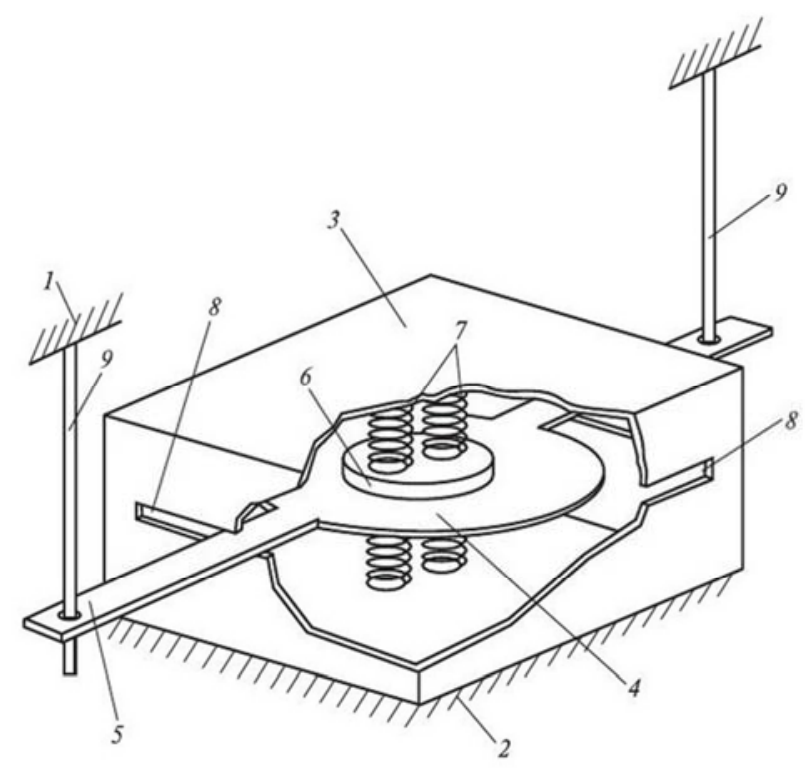

c)

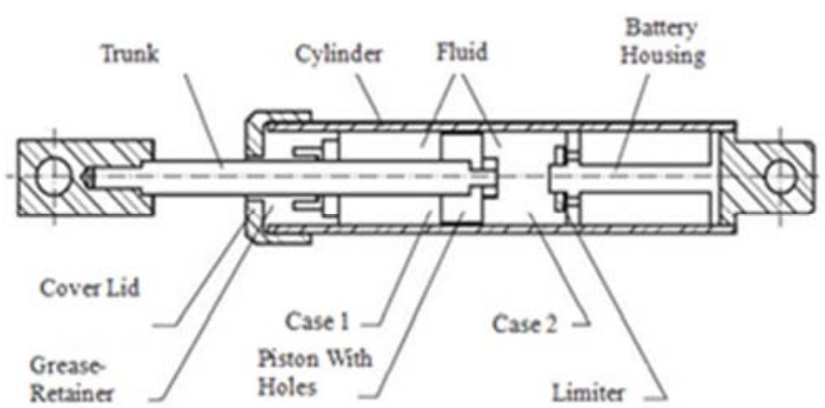

d)

Figure 8. Types of dampers: a) lead damper with a recess in the housing and with a thickening on the piston; b) a viscosity damper from Gerb; c) dry friction damper: 1, 2 - upper and lower base plates; 3 -box frame of dry friction damper; 4, 6-friction pair; 5 -console of inner friction element; 7 - spring stops; 8 - slots for free movement of the element 7; 9 - core elements; d) liquid damping device.

When considering an elastic calculation model, a seismically isolated facility described by a well-known system of linear differential equations, which in the matrix form has the following form:

$$
[M]\{\ddot{Y}\}+[B]\{\dot{Y}\}+[C]\{Y\}=-[M]\{I\} \ddot{Y}_{0}(t),
$$

Where: $[M],[B],[C]$ - respectively, the matrices of inertial terms, dissipation and stiffness;

$\{C\}$ - vector of relative shifts in the $Y O X$ coordinate system, related to the base of the structure;

$\{I\}$ - vector of direction cosines of angles between the direction of shift and vector of acceleration of the base; all components of the vector $\{I\}$, except for the last one, are assumed to be equal to one; the last one, corresponding to angular movements, is 0 ;

$\ddot{Y}_{0}(t)$ - ground acceleration.

The components of matrices $[M]$ and $[C]$ are expressed through inertial and elastic characteristics of the model.

Dispersion of energy of forced oscillations taken into account using various methods, for example, according to the Foyet's hypothesis using the Rayleigh matrices, hysteresisdamping matrices according to E. S. Sorokin.

The structure of the system of differential equations in nonlinear formulation (for example, when the structure installed on a seismic isolation system with inclusion of dry friction dampers) will be the same as in equation (1). The difference is in introduction of additive components into the equation of oscillations that reflect the influence of dry friction forces in the dampers. Calculations made using various modern software systems.

As mentioned above, any seismic isolation system has its own design features that taken into account in justifying calculations and formulating the equations of motion for seismic effects. Some recommendations in this area developed by Professor A. M. Uzdin in the paper [1]. The essential point here is to set the estimated effect for the purpose of correct assessment of the kinematic characteristics of seismic isolation. When setting the estimated effect it is necessary to exclude the distortion of the calculated accelerograms in the long-period range. 
Analysis of the majority of seismic records shows that many of them contain defects in the range of long-period vibrations. This fact can significantly distort the results of calculations and affect the assessment of the effectiveness of seismic isolation.

\subsection{Experimental Assessment}

In addition to a set of calculated analyses, an important factor in assessing the effectiveness of seismic isolation is a set of experimental studies conducted both using full-scale models and in the laboratory. These studies provide an opportunity not only to assess the actual characteristics and performance of a seismically isolated facility, but also to predict its future state during operation. It is worth mentioning the great experience gained in Kazakhstan in testing gravity-type seismic isolation and in the Kyrgyz Republic on the "sliding belt" base isolation system. Thus, the Kyrgyz Republic has become one of the largest experimental sites in the former USSR. Here we find it reasonable to discuss in more detail the existing experience in conducting experimental studies of residential buildings with a sliding belt in Bishkek (Figure 9), which was conducted by Professor I. E. Itskov, M. K. Abdybaliev (on Figure 9) and others.

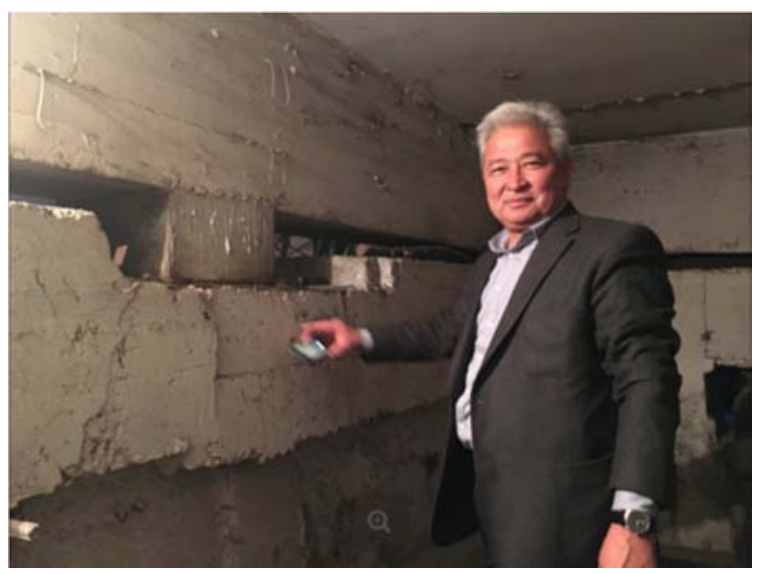

Figure 9. General view of the sliding belt in a large-panel building in Bishkek.

For the first time the sliding belt in the Kyrgyz Republic was used in 1982 in two 3-storey brick buildings of composite structure at the site with more than 9 grade seismicity. Then, in 1985, the sliding belt used in a 5-storey and 9-storey large-panel buildings of the standard 105 series with the estimated 8 -grade seismicity.

All the buildings subjected to full-scale static and vibration tests in order to study the kinematic parameters of deformation and vibrations of the aboveground structures of buildings under static and dynamic loads and to study the thresholds of triggering the sliding belt elements. Static tests carried out using hydraulic jacks, which installed in special niches at the level of the sliding belt. The vibration tests carried out using a vibration machine mounted on the coating.
The tests made it possible to prove the efficiency of the seismic isolation system in the form of a sliding belt as well as physical feasibility of the sliding processes under static and dynamic loads. The coefficient of friction at different stages of the test had a fairly stable value and ranged from 0.04 to 0.07 .

Sliding in the supports during vibration testing of a 9storey building ( $\mathrm{T}=0.4 \mathrm{~s}$ ) was recorded during the loading stages with a force applied to the vibration machine shaft of $136 \mathrm{kN}$. The dynamic response factor, which was determined as a ratio of the shear force at the level of the sliding belt to the force on the vibration machine shaft, was 23 , which is typical of large-panel buildings on dense soils. The maximum achieved force on the vibration machine shaft was $356 \mathrm{kN}$, while the shear force at the level of the sliding belt was $2,893 \mathrm{kN}$ with a building weight of $47,000 \mathrm{kN}$, and the dynamic response factor decreased to 5 , which characterizes the process of intense energy dissipation due to the dry friction forces.

The distribution of absolute accelerations and displacements along the length and height of the building showed that the maximum accelerations of the top of the buildings were $0.12 \mathrm{~g}$ with a displacement amplitude of 1.68 $\mathrm{mm}$ for a 5-storey building (in the longitudinal direction $\mathrm{T}=$ $0.165 \mathrm{~s}$ ) and $0.15 \mathrm{~g}$ with a displacement amplitude of $7.2 \mathrm{~mm}$ for a 9-storey building (in the transverse direction $\mathrm{T}=0.4 \mathrm{~s}$ ). In both cases, the buildings moved with minor deformations of the bearing structures height wise $(1.03 \mathrm{~mm}$ at $15 \mathrm{~m}$ of wall height for 5 floors and $2.7 \mathrm{~mm}$ at $27 \mathrm{~m}$ of wall height for 9 floors).

A significant reduction in the deformations of the bearing structures of buildings with a sliding belt as compared to conventional large-panel buildings is a key factor of seismic isolation system efficiency.

In general, the vibration tests carried out in 5-storey and 9storey facilities proved the accuracy of the calculation assumptions made at the design stage, the identical parameters of the static and dynamic sliding of supports and physical implementation of the processes of relative sliding in the supports with limited internal forces in the wall panels and their interfaces. The efficiency of use of the sliding supports of a combined type with inclined slip areas, designed to limit movement and return of the building to its original position during the dynamic impact, was demonstrated.

The experience of designing and building of two experimental large-panel buildings in Bishkek (former name - Frunze), the results of their field tests made it possible to carry out a comprehensive assessment of the adopted design solutions of the seismic insulation elements, adaptability to streamlined manufacture and assembly, and compliance with design requirements during the construction phase. Further improvement of the foundation and grillage design carried out in the process of development of the design solutions for 9-storey large-panel buildings during construction in residential district No. 12 of Frunze (the seismicity of the construction site was of grade 9). Prefabricated monolithic 
structures of the belt and grillage were used in the buildings, which were assembled using 14 standard sizes and manufactured at a house-building factory in special forms. Until 1990, 40 buildings had been built in the residential district No. 12. Use of the sliding belt made it possible to develop the residential district with 9-storey houses instead of 5-storey ones. Moreover, without changing the process production line, standard structures and products of the largepanel buildings were used for construction at sites with a 8 grade seismicity.

\section{Result}

Taking into account the set of calculation and theoretical and experimental studies, it was established that the effect of seismic isolation is achieved due to a certain rigidity of the seismic insulating elements. By varying it, it is possible to change the period of natural oscillations of a building, with an increase in which the seismic loads are significantly reduced by 2 or more times. As a result, it is possible to significantly simplify the engineering solutions of the bearing ground and enclosing structures, to use lighter structures, make various planning and design solutions. The main technical problem of seismic isolation, as was mentioned above, are large displacements of seismic isolators, therefore, in addition to the stiffness parameter, it is necessary to enter the vibration damping parameter. Damping shall be selected based on the condition of limiting the displacement of the building relative to the foundation by the accepted values.

The issues of damping in seismic isolation systems need to be given special attention. The damping value shall exceed a certain minimum level. With high seismicity, the recommended minimum damping for dry friction dampers (maximum resistance force) shall be at least $16 \%$ of the building weight. The search for the best suitable damping value was considered in many studies, for example, in $[1,19$, $20]$. Thus, in paper $[2,19]$, based on the results of calculation and theoretical analysis, the best suitable values of the damping parameters for mass building structures were obtained for 9, 8 and 7-grade earthquakes for linear seismic isolation with dry friction dampers. It shall be noted that the calculation and selection of parameters of seismic isolation systems, which are most prevalent in seismic resistant construction, depend on their design features. For example, for a seismic isolation system with a sliding belt, the reduction of friction forces increases the insulation efficiency, whereas the reduction of the friction force is only possible up to certain limits, which depend on the accepted displacements of the building.

\section{Discussion}

When making a decision re: the choice of seismic isolation parameters, it is desirable to have a frequency forecast of earthquakes. For high-frequency effects from small-focus earthquakes, the displacements are small and seismic isolation in the form of a seismic belt shall be an efficient option. However, the situation may change with long-period effects, when the displacements of a seismically isolated facility increase significantly. In this case, limiters are triggered, which shall be installed at a safe distance. Otherwise, when the building hits the limiters, parasitic oscillations of the system parts separated by fluoroplastic gaskets may occur at the moments of transition from joint to individual movement. The negative point in this protection are the difficulties that arise when it is necessary to regulate the friction forces. In papers [1, 21], the features of the calculation and selection of parameters for the most wellknown types of seismic isolation are considered.

Recently, more and more attention of specialists has been paid to the issues of impact of real three-component effects on the effectiveness of seismic isolation, specialists point out the objective restrictions of the efficiency of operation of the horizontal type seismically isolated systems [22-24]. It is noted that for buildings and structures with increased accountability - nuclear power plants, transport facilities, large chemical production facilities, it is advisable to use three-component seismic isolation systems. In such a system the insulation system shall be equipped with the flexible supports not only in the horizontal direction, but also in the vertical one.

\section{Conclusions}

Analysis of the issues discussed above significantly affects the effectiveness of use of a seismic isolation system of a certain type as a reliable means of seismic protection of buildings and structures. The set of these issues affects both theoretical and experimental aspects, as well as design approaches. The main ones shall be given special attention, they include:

1. Evaluation of the seismological situation, where seismic isolation is planned to be used, including engineering and geophysical surveys and seismological surveys, forecast of frequency of possible earthquakes.

2. Choice of the type of seismic insulators on the basis of technical and economic assessment.

3. Construction of calculation models (schemes) of a building, structure that actually reflect the design features of a seismically isolated facility.

4. Setting the estimated effect that shall exclude the distortion of the calculated accelerograms in the longperiod range. When performing a calculated analysis, special attention is paid setting the effect, which can be carried out using various methods and approaches, for example, using real accelerograms, modeling accelerograms by random processes, etc.

5. Building motion equations using various calculation models, either in the form of a console calculation dynamic model (for simple space-planning and design solutions), or spatial calculation dynamic models that take into account the complex design characteristics of a building and its special accountability.

6. Modelling of elements of a seismic isolating system shall take into account their real design solutions, the 
ability to move in both horizontal and vertical directions.

7. Analysis of the formulated equations of motion and seismic stability assessment of seismically isolated facilities.

8. Evaluation of the efficiency of seismic isolation shall be justified not only by way of calculations, but by way of carrying out a series of experimental studies, including model tests of individual elements, and the building as a whole.

\section{References}

[1] Uzdin A. M., Elizarov S. V., Belash T. A. Earthquake-resistant structures of transport buildings and structures: study guide. M.: Federal State Budgetary Educational Institution "Educational and Methodical Center for Education in Railway Transport". 2012. -501 p.

[2] Belash T. A. Non-traditional methods of seismic protection of transport buildings and structures: monograph. - M.: Federal State Budgetary Institution of Extended Education "Training and Methodological Center for Education in Railway Transport". 2017. -175 p.

[3] Kirikov B. N. Seismic resistance of ancient structures / Editorin-chief Ya. M. Eisenberg. The Russian Academy of Science. Interdepartmental Council of Seismology and Antiseismic Construction. - M.: Science. 1992. - 136 p.

[4] SNiP II-7-81* Construction in seismic regions. Moscow: Gosstroy of Russia, State Unitary Enterprise Center for Support of Entrepreneurs, $2000-44$ p.

[5] SP 14.13330.2014. Construction in seismic areas. - Put into effect on 2014-06-01. M.: Ministry of Construction of Russia, 2014. $-126 \mathrm{p}$.

[6] Martelli A., Forni M., Clemente P. "Recent worldwide application of seismic isolation and energy dissipation and conditions for their correct use". Antiseismic construction. Safety of buildings. 2013 No. 6. P. 52-59.

[7] Martelli A., Bettinali F. Status report on activities on seismic isolation in Italy (IAEA Specialists meeting on seismic isolation technology, San Jose, California, USA, March 18-20, 1992), Proceedings, p. 56-74.

[8] Kelly J. M. Earthquake resistant design with rubber Springer, 1997. $-243 \mathrm{p}$.

[9] Kelly J. M. Base Isolation in Japan, 1988. Report NO UCB/EE-RC-88/20, University of California, Berkeley, 1988.

[10] Zelenkov F. D. Protection of buildings and structures from damage using a shock absorber. - M.: Nauka, 1979.

[11] Zhunusov T. Zh. Modern problems of seismic resistant construction //KazNIISSA. Studies of seismic resistance of structures and buildings. Collection of papers of the Institute, issue 21 (31). KazNIISSA, 2006.
[12] Cherepinsky Yu. D., Lapin V. A. Basics of seismic isolation in construction. - Almaty, 1995.

[13] Cherepinsky Yu. D. Seismic isolation of residential buildings. - Almaty: KazGASA, 2003.

[14] Kilimnik L. Sh., Soldatova L. L., Lyakhina L. I. Analysis of performance of buildings with a sliding belt using a multi-mass computational model// Construction mechanics and structural analysis. -1986 , No. 6. P. 69-73.

[15] Polyakov S. V., Kilimnik L. Sh. Recommendations for the design of buildings with a seismic insulating sliding belt and elastic displacement limiters//Express information VNIIIS (A. N. Lodygin All-Russian Scientific Research Institute of Light Sources). Ser. 14. 1982, No. 4. P. 7-11.

[16] Polyakov S. V., Kilimnik L. Sh., Soldatova L. L. Experience in the construction of buildings with a seismic insulating sliding belt in the foundation. - M.: Stroyizdat, 1984.

[17] Eisenberg Ya. M. Seismic isolation and adaptive seismic protection systems. - M.: Nauka, 1983.

[18] Savinov O. A., Sandovich T. A. On some features of use of systems of seismic isolation of buildings and structures // Izv. Vedeneev VNIIG. Collection of scientific papers. 1982. - V. 161. P. 26-33.

[19] Belash T. A., Albert I. U. Use of dry friction energy absorbers in seismic systems of buildings and structures // Antiseismic construction. 1995. - ed. 5. P. 35-41.

[20] Dolgaya A. A., Sandovich T. A. (Belash T. A.), Uzdin A. M. Selection of Parameters of Seismoisolation Foundation. Proceedings of Eleventh World Conference on Earthquake Engineering. Acapulco. Mexico. June 23-28. 1996.

[21] Belash T. A., Albert I. U. Comparative analysis of seismic resistance of buildings with different systems of seismic isolation // Antiseismic construction. 1995. - ed. 4. P. 30-34.

[22] Sasaki et. al. (2012) NEES/E-Defence Base-Isolation Tests: Effectiveness of Friction Pendulum and Lead-Rubber Bearings Systems //Proc of the 15 WCEE Conf. Lisboa (Portugal).

[23] S. Furukawa et al/ (2013) Comparison of Vertical Dynamic Response Characteristics of Two Base-isolated Buildings based on Full-scale Table Test // Proc. of the 13 WCSI. Sendai (Japan).

[24] Belyaev V. S., Kostarev V. S., Vasilyev P. S. Dynamics of natural seismically isolated buildings. Scientific papers of the International Scientific and Practical Conference. - Almaty: KazNIISSA, 2017. - 146 p.

[25] Orunbaev S. J., Mendekeev R. A., Moldobekov B. D., Rodkin M. V. Microseismic and Vibroseismic Testing of a House: Comparative Study of Results with the Example of a Typical Privately Owned Residential House in Bishkek, Kyrgyzstan // ISSN 0747-9239, Seismic Instruments, C Allerton Press, Inc., 2019, Vol. 55, No. 1, pp. 92-100. 